\title{
NASA Research Center Contributions to Space Shuttle Return to Flight (SSRTF)
}

\author{
Charles E. Cockrell, Jr. , Robert S. Barnes ${ }^{\dagger}$, and Harry L. Belvin ${ }^{\ddagger}$ \\ NASA Langley Research Center, Hampton, VA \\ John Allmen ${ }^{\S}$ \\ NASA Ames Research Center, Moffett Field, CA \\ Angel Otero ${ }^{* *}$ \\ NASA Glenn Research Center, Cleveland, $\mathrm{OH}$
}

\begin{abstract}
Contributions provided by the NASA Research Centers to key Space Shuttle return-toflight milestones, with an emphasis on debris and Thermal Protection System (TPS) damage characterization, are described herein. Several CAIB recommendations and Space Shuttle Program directives deal with the mitigation of external tank foam insulation as a debris source, including material characterization as well as potential design changes, and an understanding of Orbiter TPS material characteristics, damage scenarios, and repair options. Ames, Glenn, and Langley Research Centers have performed analytic studies, conducted experimental testing, and developed new technologies, analysis tools, and hardware to contribute to each of these recommendations. For the External Tank (ET), these include studies of spray-on foam insulation (SOFI), investigations of potential design changes, and applications of advanced non-destructive evaluation (NDE) technologies to understand ET TPS shedding during liftoff and ascent. The end-to-end debris assessment included transport analysis to determine the probabilities of impact for various debris sources. For the Orbiter, methods were developed, and validated through experimental testing, to determine thresholds for potential damage of Orbiter TPS components. Analysis tools were developed and validated for on-orbit TPS damage assessments, especially in the area of aerothermal environments. Advanced NDE technologies were also applied to the Orbiter TPS components, including sensor technologies to detect wing leading edge impacts during liftoff and ascent. Work is continuing to develop certified TPS repair options and to develop improved methodologies for reinforced carbon-carbon (RCC) damage progression to assist in on-orbit repair decision philosophy.
\end{abstract}

\section{Nomenclature}

$\begin{array}{ll}\text { AEDC } & \text { Arnold Engineering Development Center } \\ \text { AFTF } & \text { Aerodynamic Flight Test Fixture } \\ \text { ARC } & \text { Ames Research Center } \\ \text { BTA } & \text { Booster Trowelable Assembly } \\ \text { CAIB } & \text { Columbia Accident Investigation Board } \\ \text { CFD } & \text { Computational Fluid Dynamics } \\ \text { COTS } & \text { Commercial Off-the-Shelf } \\ \text { DTA } & \text { Debris Transport Analysis }\end{array}$

\footnotetext{
* Aerosciences and Flight Systems R\&T Manager, Exploration Systems and Space Operations Technology Directorate (Formerly, Space Shuttle RTF Deputy Manager), MS 172, Hampton, VA, 23681. AIAA Senior Member. ${ }^{\dagger}$ Project Manager, LaRC Space Shuttle RTF Project Office, MS 173, Hampton, VA, 23681. AIAA Senior Member.

‡ Deputy Project Manager, LaRC Space Shuttle RTF Project Office, MS 173, Hampton, VA, 23681.

$\S$ Systems and Project Engineering Branch, NASA Ames Research Center, Moffett Field, CA, 94035

** Chief, Space Operations Division, Mail Stop 86-1, 21000 Brookpark Road, Cleveland, OH, 44135
} 


$\begin{array}{ll}\text { ET } & \text { External Tank } \\ \text { EVA } & \text { Extravehicular Activity } \\ \text { GRC } & \text { Glenn Research Center } \\ \text { HFFF } & \text { Hypervelocity Free Flight Facility } \\ \text { IHF } & \text { Interaction Heating Facility } \\ \text { IR } & \text { Infrared } \\ \text { IVA } & \text { Intravehicular Activity } \\ \text { LaRC } & \text { Langley Research Center } \\ \text { LAL } & \text { Langley Aerothermodynamics Laboratory } \\ \text { LAR } & \text { Large Area Repair } \\ \text { LH2 } & \text { Liquid Hydrogen } \\ \text { LO2 } & \text { Liquid Oxygen } \\ \text { MCC } & \text { Marshall Convergent Coating } \\ \text { MLGD } & \text { Main Landing Gear Doors } \\ \text { NASA } & \text { National Aeronautics and Space Administration } \\ \text { NCFI } & \text { North Carolina Foam Industries } \\ \text { NDE } & \text { Nondestructive Evaluation } \\ \text { PAL } & \text { Protuberance Air Load } \\ \text { PIV } & \text { Particle Imaging Velocimetry } \\ \text { RCC } & \text { Reinforced Carbon-Carbon } \\ \text { RTV } & \text { Room Temperature Vulcanizing } \\ \text { SAR } & \text { Small Area Repair } \\ \text { SLA } & \text { Super Lightweight Ablator } \\ \text { SOFI } & \text { Spray-On Foam Insulation } \\ \text { SRB } & \text { Solid Rocket Booster } \\ \text { STS } & \text { Space Transportation System } \\ \text { TAR } & \text { Tile Area Repair } \\ \text { TGA-MS } & \text { Thermogravimetric Mass Spectrometer } \\ \text { TPS } & \text { Thermal Protection System } \\ \text { WLE } & \text { Wing Leading Edge } \\ & \end{array}$

\section{Introduction}

W ASA Research Centers provided significant technical contributions to the Space Shuttle program to accomplish the goal of returning the Shuttle safely to flight, the first objective of the Vision for Space Exploration. ${ }^{1}$ In particular, significant accomplishments were made in an effort to address the recommendations of the Columbia Accident Investigation Board (CAIB) regarding mitigation of potential debris sources, material characterization of the Orbiter Thermal Protection System (TPS), TPS damage assessments, TPS repair options and enhancing the ability of the Orbiter to re-enter the atmosphere with minor TPS damage. ${ }^{2}$ The scope of work to contribute to these objectives included assessments of basic physical properties, design enhancements, environments, analysis tool development, and flight hardware development. Ongoing work includes development and demonstration of TPS repair concepts as well as analysis tool maturation.

Support for return-to-flight activities grew directly out of work to support the Columbia Accident Investigation Board (CAIB). Experimental testing and analysis conducted at Langley Research Center on aerothermodynamic characteristics of the Shuttle Orbiter during re-entry led to an assessment of the root cause of the accident. ${ }^{3}$ In addition, technical support was provided in the areas of advanced Nondestructive Evaluation (NDE) technologies applied to the External Tank (ET) spray-on-foam-insulation (SOFI); evaluation of the Orbiter reinforced carboncarbon (RCC) wing leading edges (WLE) during impact testing; physics-based modeling to determine energy levels of impact testing; and structures and materials analysis on debris recovered from the accident. ${ }^{4,5}$ The Columbia Accident Investigation Board (CAIB) report (also commonly known as the Gehman Commission Report) was published in August 2003. The root cause of the Columbia accident was determined to be a breach in the wing leading edge caused by impact of foam debris, originating from the left bipod region of the external tank. For this reason, a substantial number of CAIB recommendations dealt with understanding and mitigating debris sources and 
resulting damage. NASA committed to implementing all of the CAIB findings and recommendations and sought to "raise the bar" in a number of areas.

The NASA Research Centers contributed significantly to addressing recommendations dealing with the mitigation of debris sources from the External Tank and ensuring the robustness of the Orbiter's TPS components to re-enter the atmosphere safely. Efforts directed at the external tank included evaluation of ET redesign concepts, characterization of ET TPS, and application of advanced NDE technologies to better understand mechanisms which may contribute to ET foam liberation. Activities directed at the Shuttle Orbiter include model development, testing, analysis to characterize WLE impact and damage tolerances; experimental testing and analysis to characterize RCC material properties and damage progression; development, validation, and application of aerothermal analysis tools to define re-entry flow field environments for nominal and damaged TPS scenarios; application of advanced NDE technologies to understand TPS damage states; and development of on-orbit TPS repair options. Support was also provided for Shuttle systems engineering and integration activities, specifically an end-to-end assessment of the debris environment, which included a debris transport analysis (DTA), validated through experimental testing and computational analyses.

\section{External Tank Redesign and TPS Characterization}

CAIB Recommendation 3.2-1 called for NASA to "Initiate an aggressive program to eliminate all External Tank (ET) Thermal Protection System (TPS) debris-shedding at the source with particular emphasis on the region where the bipod struts attach to the External Tank". ${ }^{2}$ The spray-on-foam-insulation (SOFI), applied to the external tank to keep external temperatures high enough to limit ice and frost formation when cryogenic fuels are added to the tank, has been analyzed as a potential source of debris that could cause damage to the Orbiter if liberated during ascent. Foam may be liberated from the ET due to mechanisms that may originate from manufacturing or processing flaws. Several areas of technology development were pursued to assist in minimizing ET foam as a source of debris.

- Independent technical reviews, target analyses, and tests of External Tank (ET) redesign concepts were performed. The forward bipod fitting was redesigned in order to mitigate liberation of foam from this region. An assessment of localized heating due to shock interference effects in the bipod region was performed through analysis and computations in order to determine effects on the ascent aeroheating database.

- LaRC performed assessments of analytical tools, test methods, and the availability of material characterization data relevant to the problem of SOFI shedding from the ET. ${ }^{6}$

- Studies regarding material property characterization, constitutive modeling, fracture characterization, failure modes and criteria, aging, cryopumping, and failure progression relevant to the ET TPS were performed. A thermogravimetric analyzer-mass spectrometer (TGA-MS) was used in the chemical identification of materials that come from a system during heating from room temperature to the decomposition temperature of the material. This technique was used to determine what materials are being released from the ET during ascent and what chemical reactions may be occurring. A photograph of the mass spectrometer device is shown in figure 1 .

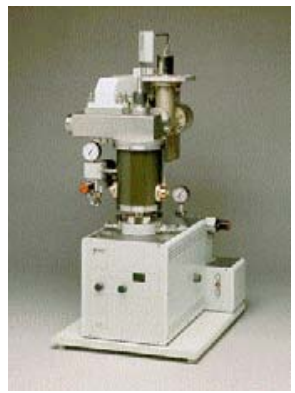

Figure 1: TGA-Mass Spectrometer for assessment of ET Foam Shedding. 
- LaRC developed advanced terahertz NDE imaging technology for application to the ET TPS. Terahertz imaging has been previously applied to inspect the Shuttle tile bondlines for defects. ${ }^{7}$ This technology is being applied to the ET to detect manufacturing or processing flaws that could lead to liberation of foam during ascent. Figure 2 shows an example of the implementation of this device. The figure shows a SOFI test panel for one of the protuberance airload (PAL) ramps from the External Tank, and a terahertz image of the test panel. Additional detail on NDE technology development and application for the external tank will be addressed in reference .
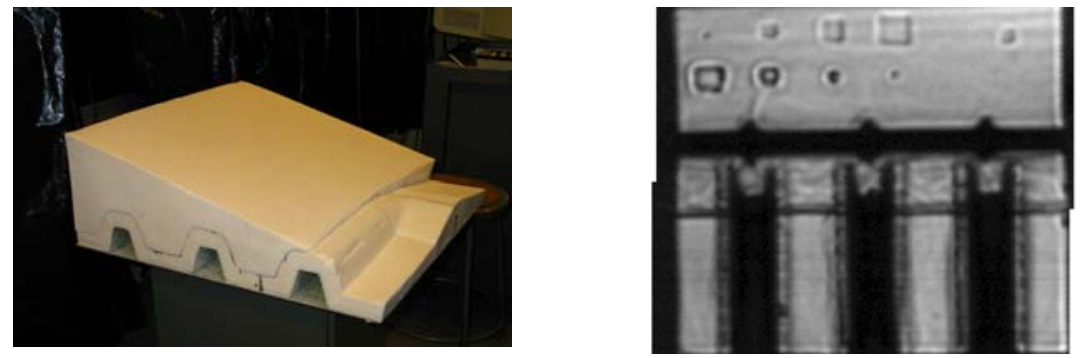

Figure 2. Application of Terahertz imaging to SOFI test panels on the External Tank.

- The aeroelastic stability of the Liquid Oxygen (LO2) and Liquid Hydrogen (LH2) cable trays were assessed with and without the protective Protuberance Air Load (PAL) ramps. The PAL ramps are in place on the ET to protect the liquid Oxygen and Hydrogen cable trays from high-velocity cross flows. An effort is underway to determine if the PAL ramps can be removed in order to minimize the quantity of foam in this region. Experimental testing was accomplished in the AEDC 16T tunnel to evaluate the potential for removing the PAL ramps. Figure 3 shows a model used for testing the $16 \mathrm{~T}$ wind tunnel at Arnold Engineering Development Center (AEDC) for this purpose. ${ }^{9}$ The photograph shows an aluminum model with the LH2 trays, the PAL ramp, the two re-pressurization lines (Gaseous Hydrogen and Gaseous Oxygen), and the 17-inch Liquid Oxygen supply line model. Additional detail on this study is presented in reference 9. LaRC led the test planning, conduct, and data analysis for the AEDC testing. GRC also conducted PAL ramp tests in the 8' $\mathrm{x}^{\prime}$ ' Wind Tunnel at NASA-GRC to investigate aerodynamic characteristics of the STS stack with the PAL ramps removed.

- The LaRC Impact Dynamics Research Facility conducted studies to determine strain-rate effects for TPS foam and ablative materials. Tests were performed on several materials, including NCF124-124, the acreage material which is automatically applied in a controlled environment, and BX-265, a polyurethane foam which is applied by hand in "close out" regions. Testing also included ablator materials SLA-561M/S (material applied to the cable trays, bipod, and other areas prior to application of close-out foam), RT-455 (applied to fasteners), MCC-1 (modified ablator material applied to the solid rocket booster (SRB) forward assembly), BTA, and the SRB rocket nozzle-cap. Test results from each material were used to determine debris allowables during lift-off and ascent.

- GRC contributed to the thermostructural analysis of ET foam application. This effort included verification of micromechanics models using BX265 foam structure and mechanical properties.

- ARC also conducted studies to determine the microstructure and mechanical properties of BX and NCFI foams.

Ames Research Center (ARC) contributed to a debris transport analysis (DTA) in order to assess the potential of debris sources, including foam and ice liberated from the ET, to strike the Orbiter and cause damage to windows, RCC, and tile. The DTA includes computational fluid dynamics (CFD) analyses using the CART3D and OVERFLOW Navier-Stokes codes. Predictions were anchored by experimental testing in the ARC 9-x-7-foot Wind Tunnel and other facilities. Particle Imaging Velocimetry (PIV) was used to obtain flow field velocity data to validate CFD predictions for conditions of interest. Additionally, testing in the Ames Hypervelocity Free Flight 
Facility (HFFF) was conducted in order to obtain aerodynamic predictions for geometries representative of ET foam "divots", liberated pieces of foam caused by manufacturing flaws. The freestream velocity predictions, along with the debris source models, were used to construct aerodynamic and transport models of debris. The end product of the end-to-end debris assessment included predictions of impact locations and kinetic energy values.

Dryden Flight Research Center (DFRC) also contributed to the DTA by conducting a flight experiment to validate the CFD_predicted debris transport models. The Dryden Aerodynamic Flight Test Fixture (AFTF), mounted beneath an F-15B aircraft, was used to eject "divot" shaped pieces of foam to simulate ET foam debris liberation. Trajectory and orientation at flight speeds up to Mach 2 were recorded in order to validate aerodynamic models of debris sources.

\section{Space Shuttle Orbiter}

The NASA Research Centers supported the implementation of several CAIB Report recommendations related to the Orbiter TPS robustness, damage assessments, and characterization. The scope of these efforts included both the RCC wing leading edge (WLE) and the acreage tiles applied to the lower surface of the fuselage and wings. Specific CAIB recommendations that were addressed by these efforts include:

- R3.3-1: Develop and implement a comprehensive inspection plan to determine the structural integrity of all Reinforced Carbon-Carbon (RCC) system components.

- R3.3-4: In order to understand the true material characteristics of Reinforced Carbon-Carbon components, develop a comprehensive database of flown RCC material characteristics by destructive testing and evaluation.

- R3.8-2: Develop, validate, and maintain physics-based computer models to evaluate Thermal Protection System damage from debris impacts. These tools should provide realistic and timely estimates of any impact damage from possible debris from any source that may ultimately impact the Orbiter. Establish impact damage thresholds that trigger responsive corrective action, such as on-orbit inspection and repair, when indicated.

- R6.4-1: Develop a practicable capability to inspect and affect emergency repairs to the widest possible range of damage to the Thermal Protection System, including both tile and Reinforced Carbon-Carbon. This inspection plan should take advantage of advanced non-destructive inspection technologies.

Activities to implement these recommendations, as well as "raise the bar" program directives, included a comprehensive material test program to determine material properties of RCC and tile, application of NDE inspection technologies to assess tile and RCC damage, validation and application of methods to assess impact tolerance thresholds due to debris impacts, and development of methods to assess progression of RCC damage. Additionally, on-orbit repair concepts for both tile and RCC were formulated, and computational and experimental methods were developed and applied to assess the aerothermal environments for TPS damage and repair scenarios. This work also contributed to the formulation of on-orbit TPS inspection criteria and repair requirements. 
LaRC led the development, validation, and application of a dynamic finite-element analysis code, LS-DYNA, to model the effects of debris sources striking the RCC panels and acreage TPS tiles. Application of this method was used to predict kinetic energy levels that would cause damage to TPS elements. These predictions were used to assess impact tolerance thresholds, in the form of kinetic energy levels to cause RCC damage, and contributed to the end-to-end debris environment assessment, as well as TPS inspection and repair requirements. Impact of various debris sources (including foam, ice, ablator materials and other non-TPS related debris sources) were within the scope of this activity. Modeling parameters included debris material, debris geometries, impact velocities, trajectories, locations on the RCC panels, and different RCC panels. ${ }^{10-12}$

To validate the LS-DYNA physics-based model, testing of foam and other debris impacts on RCC, TPS tiles, and windows were conducted. The GRC Ballistic Impact Team conducted extensive impact testing on Orbiter RCC panels, tile samples, and windows. These tests provided data on impact damage from various debris sources over a range of masses, impact speeds, and impact locations. Figure 4 shows ice characterization testing conducted in the GRC Ballistic Impact Facility. Material testing of RCC, foam, ice, and ablator materials was conducted to determine strain-rate effects and provide data for material modeling in the analyses. LaRC conducted dynamic testing of foam, dynamic coupon testing of RCC, and dynamic panel testing of RCC, with and without pre-stress expected due to aerodynamic loading.

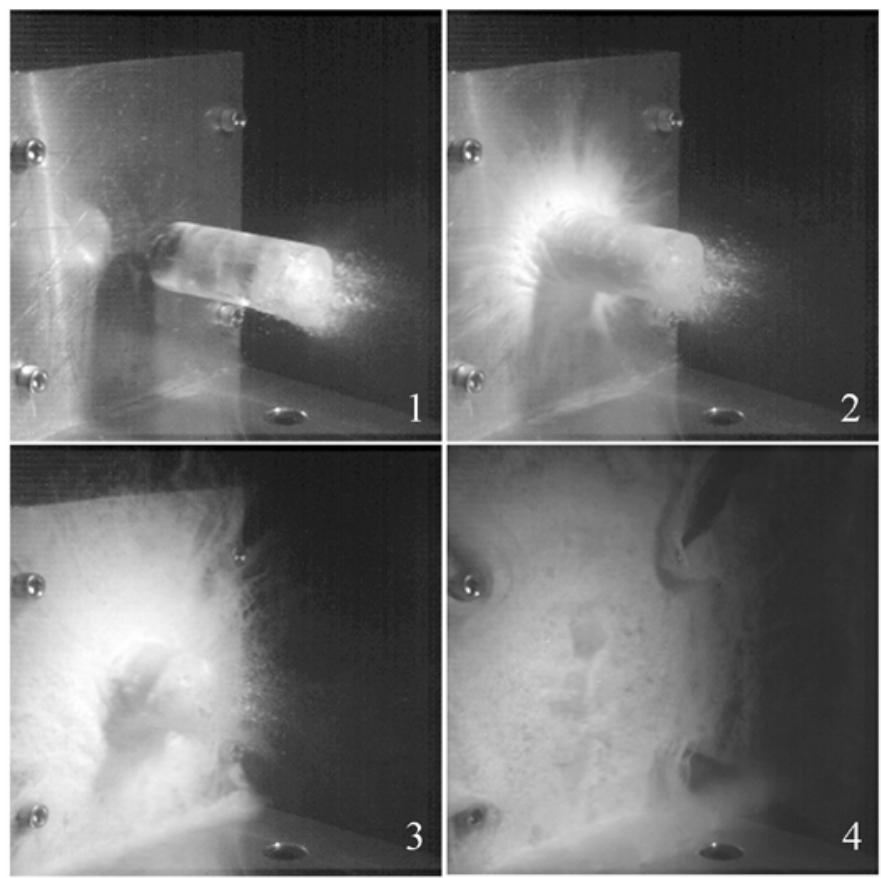

Figure 4. Ice Characterization Testing in the GRC Ballistic Impact Test Facility.

LS-DYNA production runs were conducted by GRC and LaRC, as well as Boeing-Philadelphia, to build a matrix of impact predictions. Figure 5 shows an example of LS-DYNA validation for ice impact testing. Predictions were also correlated with coupon and full-scale RCC test data, conducted at Southwest Research Institute. ${ }^{13}$ Figure 6 shows the test set-up for a full-scale foam impact test of RCC panel 8 at Southwest Research Institute using a 1.68$\mathrm{lbm}$ foam test article at $777 \mathrm{ft} / \mathrm{sec}$ impact velocity. Figure 7 shows a simulation of the impact and damage to this panel using LS-DYNA. The impact angle and velocity were prescribed in the calculation based on test data. Additional 3-point static bend tests with RCC coupon samples were conducted at LaRC to correlate predictions with physical damage states that deal with surface delaminations to RCC. 

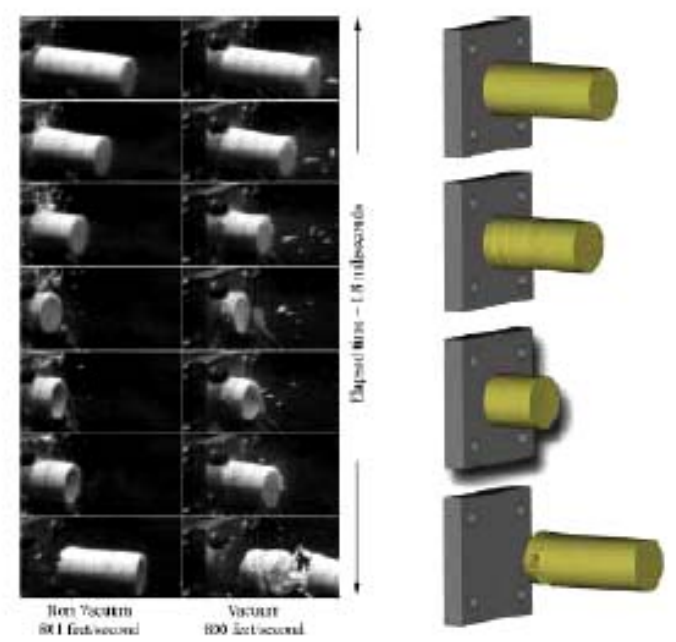

Figure 5. LS-DYNA Validation of Ice Impact Testing.

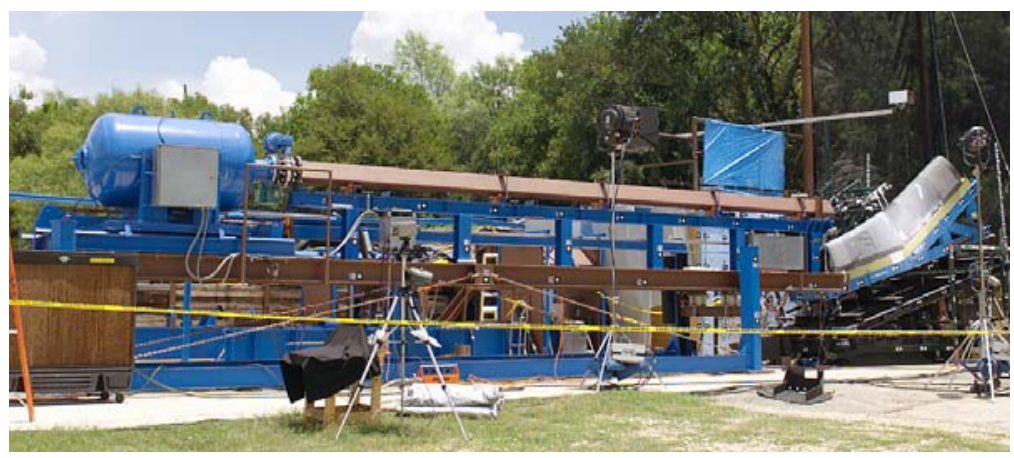

Figure 6: Full-Scale RCC Panel Impact Test at Southwest Research Institute
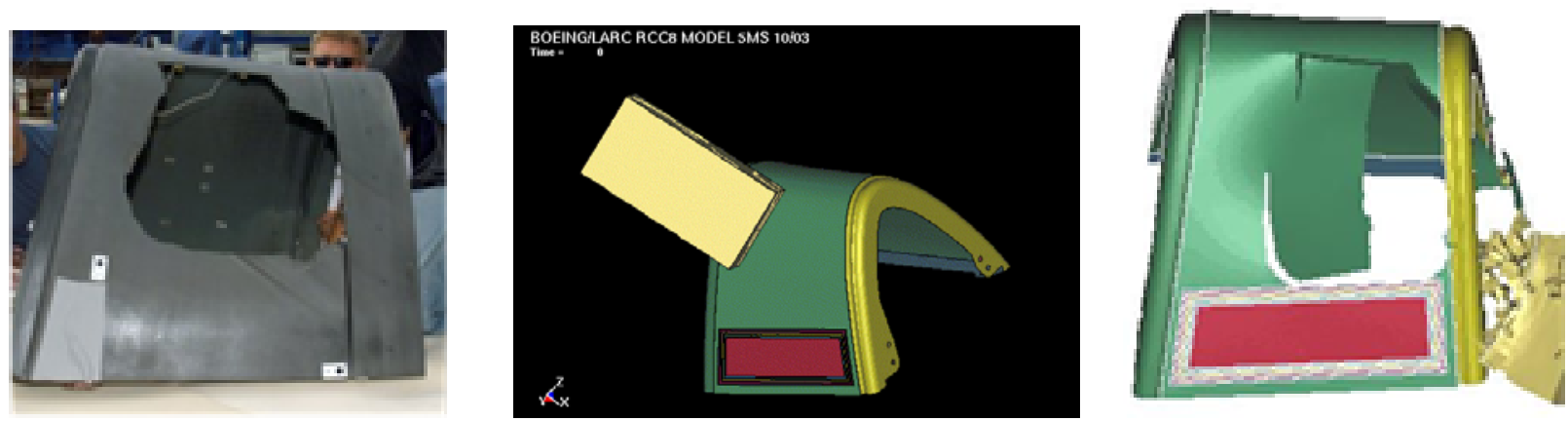

Figure 7: Simulation of foam impact damage of RCC panel 8 using LS-DYNA.

LaRC conducted experimental testing and analysis to better characterize RCC material properties and examine progression of damage and structural degradation impacts of damage scenarios for RCC leading edge components. This included material property testing in the Langley Materials Research Laboratory to develop fundamental mechanics and fracture toughness parameters for RCC material. ${ }^{19}$ Correlation of test and analysis methods for damage progression, as well as application of three-dimensional finite element methods to specific damage scenarios is continuing. A previously-flown RCC Panel 6L, which sustained a through crack during foam impact testing, is being analyzed for crack propagation effects. Following STS-114, additional RCC element tests will be conducted in 
order to further mature analysis methods for damage progression. The objective is to apply these methods as a predictive tool to determine the response of damage scenarios under representative thermal and mechanical loads. The results will contribute to assessments of damage criticality and potentially to entry vs. repair decisions for onorbit damage states.

To support assessments of TPS viability under nominal re-entry and possible damage scenarios, experimental and computational investigations are being conducted to define the re-entry aerothermal environment for the Orbiter. Two critical analysis tools were developed for application prior to the STS-114 mission. First, a cavity heating tool was developed in order to determine local heating augmentation factors due to missing or damaged tile areas on the Orbiter. Figure 8 shows a photograph of potential tile damage on the lower surface of the Orbiter in the form a cavity that results from missing tile. LaRC conducted experimental testing to develop a database of localized heating factors for tile cavities. Figure 9 shows resultant heating for one case, based on phosphor thermography measurements obtained in the LaRC 20-Inch Mach 6 wind tunnel. ${ }^{15-17}$ (This facility is part of the Langley Aerothermodynamics Laboratory (LAL), a suite of four conventional hypersonic wind tunnels which were utilized extensively in CAIB and return-to-flight experimental test support.) Both LaRC and ARC have applied computational fluid dynamics (CFD) tools to develop the cavity heating correlations further and determine appropriate ground-to-flight scaling factors for localized cavity heating factors. Second, LaRC developed a boundary-layer transition prediction tool, which was developed to provide an additional predictive tool to determine if damaged TPS scenarios may result in early transition to turbulent flow during re-entry. The tool represents an update to existing Orbiter boundary layer transition databases. ${ }^{18}$ The scope of the boundary layer tool development includes factors for protuberances, cavities, and ablation products due to application of repair materials. Figure 10 shows experimental phosphor thermography measurements on a model with forced-transition devices ("trips") to simulate a protuberance resulting from tile damage and repair. These conditions are simulated in wind-tunnel facilities by modeling local surface blowing with the use of high-pressure air. Maturation of this tool will continue following STS-114 through additional experimental testing and analysis correlations.

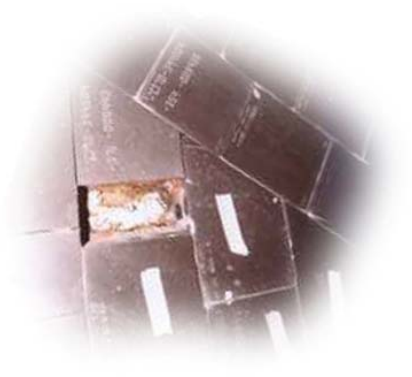

Figure 8: Damaged Tile

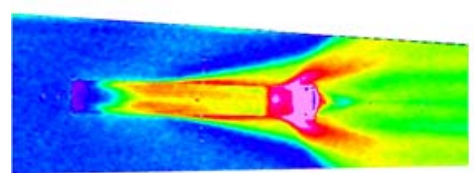

Figure 9: Resultant Cavity Heating

ARC is also conducting CFD simulations to develop approaches for applying high-fidelity Navier-Stokes calculations for assessments of on-orbit damage in the future. ${ }^{19} \mathrm{LaRC}$ is developing a grid-morphing approach that may be incorporated in high-fidelity CFD assessments to investigate potential damage scenarios in the event of debris impacts during Shuttle missions. Figure 11 shows an example of a CFD solution obtained by removing grid elements and replacing those elements with simulated wing leading-edge damage. Finally, experimental and computational studies are continuing to mature models for RCC breech heating. ${ }^{21}$ 


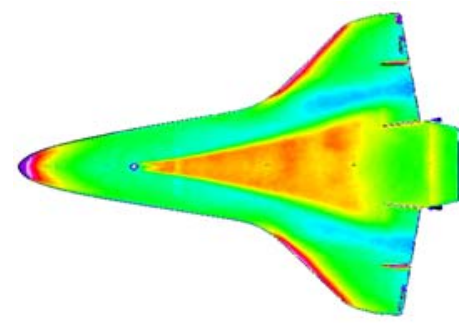

Figure 10: Experimental measurements of boundary-layer transition.

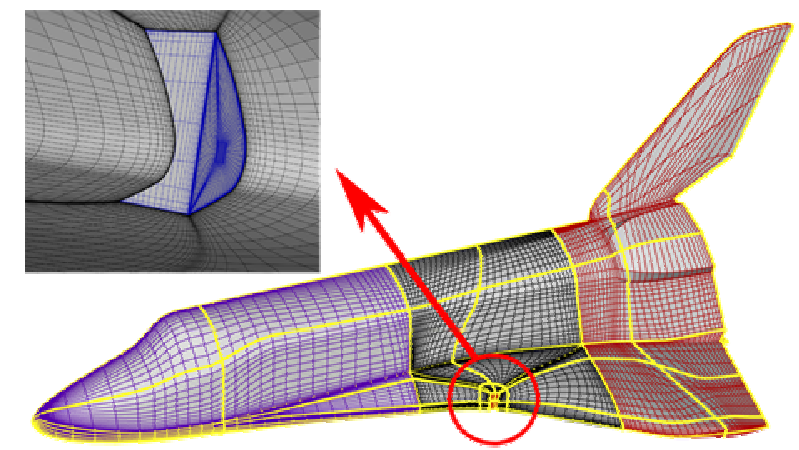

Figure 11: Grid Generation for CFD predictions of RCC Wing Leading Edge Damage.

LaRC is contributing to efforts in the formulation of on-orbit inspection concepts and TPS repair concepts that will be fully matured following return-to-flight. A hand-held infrared (IR) thermography camera system is planned for an on-orbit demonstration during STS-121 and will be evaluated as an additional on-orbit inspection capability to detect surface coating loss, delaminations, and cracks in RCC material. LaRC is leading the integration and flight qualification testing of a commercial off-the-shelf (COTS) system for this application.

LaRC is leading a team developing an RCC plug repair concept, designed to repair a through-crack in an RCC panel up to 4.0-inches in diameter. The concept, illustrated in figure 12, consists of a flexible Carbon SiliconCarbide (C-SiC) cover plate, attachment mechanism, and t-bar assembly. Evaluation of this repair concept will also be accomplished through an Intravehicular Activity (IVA)on the mid-deck for STS-114, which will examine operational aspects of the plug repair concept and tools in a microgravity environment, and an EVA demonstration for STS-121. Additionally, LaRC developed an ultrasonic database characterizing impacts to the wing leading edge, wing acreage, carrier panels in foam and hypervelocity impacts. This led to developing specifications of an ultrasonic system for characterizing location and energy of impacts on Space Shuttle that supported development of a Wing Leading Edge Sensor Subsystem. LaRC is leading additional research and development options for small and large area TPS damage repair, with involvement from both GRC and ARC. Prototype hardware is slated for development and possible payload inclusion for STS-115 (Small Area Repair or SAR - repairs holes less than .25" diameter), STS-116 (Tile Area Repair or TAR), and STS-117 (Large Area Repair or holes up to 16” diameter) missions. LaRC is developing a flexible patch concept, fasteners, and on-orbit repair tools for small-area RCC repair and is leading activities for large-area tile repair. GRC is developing gaskets and sealants for repair concepts, including the large-area tile repair. LaRC is also leading the development of large-area RCC repair concepts, including flexible ceramic and metallic over-wrap solutions with contributions from GRC. ARC Arc-Jet facilities are being utilized to test the various RCC repair concepts. Numerous tests have been conducted in the 60 MW Interaction Heating Facility (IHF). ${ }^{28}$ The ARC arc-jet test data led to improvements in the RCC plug and crack repair concepts, which are scheduled for on-orbit demonstrations during the STS-114 and STS-121 missions. 


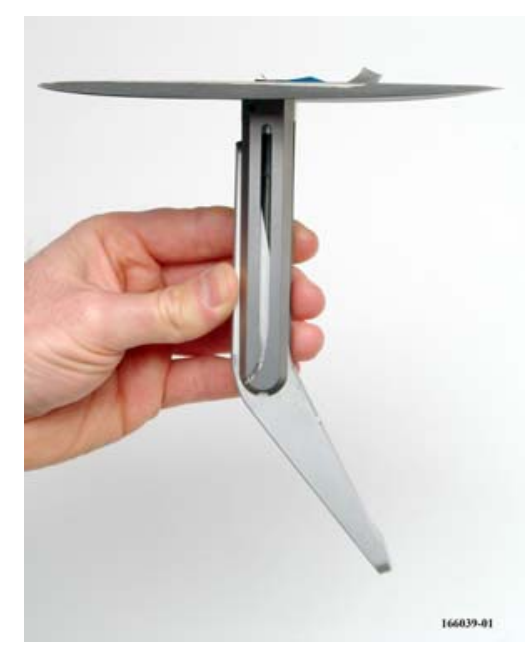

Figure 12. RCC Plug Repair Concept.

Finally, LaRC conducted investigations of alternative tile repair materials. ${ }^{23}$ Room Temperature Vulcanizing (RTV) silicones have several properties that make them possible candidates for on-orbit repair materials. Vacuum and zero net-gravity tests were accomplished to assess material characteristics. Figure 13 illustrates application of an ablative tile repair material on a damaged tile sample and figure 14 shows a commercial dispenser used for demonstration of a candidate RTV repair material.

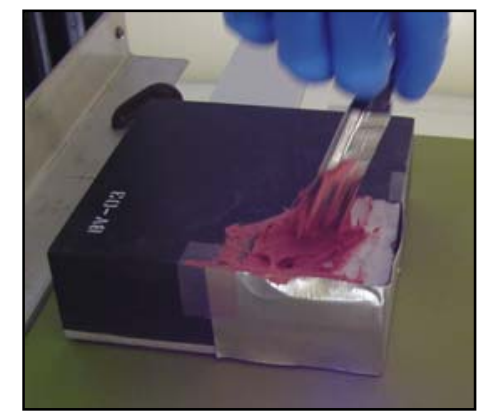

Figure 13. Tile Repair

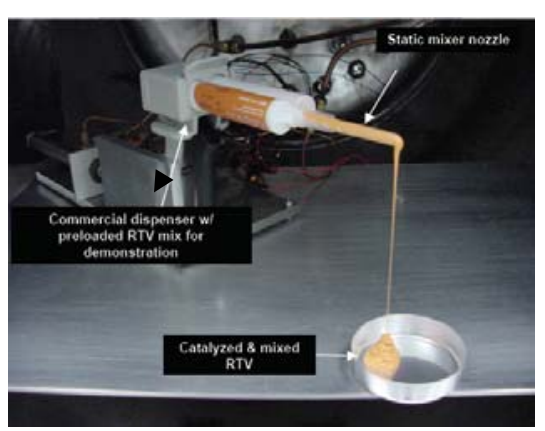

Figure 14. Tile Repair Patch Dispensing

\section{Other Efforts}

The research centers contributed to other Space Shuttle program efforts not related to thermal protection system enhancements or characterization, including the following:

- LaRC is conducting an assessment of Shuttle roll-out fatigue loads.

- LaRC analyzed the Rocket Control System (RCS) thruster nozzles for crack propagation as a result of corrosion. 
- GRC and LaRC supported investigations of rudder speed brake and body-flap actuator gear wear, damage, and degradation issues.

- GRC investigated environmental seals for the main landing gear doors (MLGD) of the Shuttle orbiter. GRC seals experts performed seal leakage and compression tests to achieve optimal seal performance and address MLGD closure problems after new seals were installed on the Discovery.

\section{Concluding Remarks}

The NASA Research Centers made significant contributions to return the Space Shuttle safely to flight, the first step in the Vision for Space Exploration. Langley, Glenn, and Ames Research Centers performed analytic studies, conducted ground testing, and developed analysis tools and flight hardware to address Columbia Accident Findings and Recommendations as well as program directives designed to "raise the bar". Significant work was accomplished to determine the material properties of External Tank Thermal Protection Systems (TPS), the nature of TPS-related debris sources from the external tank, design changes to the tank to mitigate debris sources, and transport mechanisms to better define the debris environment during ascent. Methodologies were developed to assess damage tolerances for the Orbiter TPS (tile and wing leading edge), damage propagation of RCC material, and aerothermal environments of TPS damage and repair scenarios. Advanced non-destructive evaluation (NDE) and sensor technologies were developed and applied to understand the nature of ET TPS shedding, debris impacts on the Orbiter wing leading edge, and Orbiter TPS damage. Work is continuing to develop certified TPS repair capabilities and to contribute to decision rationale for on-orbit repair decisions. The NASA Research Centers are proud to be a part of the One NASA Team contributing to this historic endeavor. In the words of President George W. Bush following the Columbia accident: "The cause in which they died will continue. Mankind is led into the darkness beyond our world by the inspiration of discovery and the longing to understand. Our journey into space will go on.”

\section{References}

1. The Vision for Space Exploration. National Aeronautics and Space Administrator, Washington, D.C., February 2004.

2. Report of the Columbia Accident Investigation Board. Government Printing Office, Washington, D.C., August 2003.

3. Horvath, Thomas J. "Experimental Aerothermodynamics Support In Support of the Columbia Accident Investigation”, AIAA paper 2004-1387, Presented at the $42^{\text {nd }}$ AIAA Aerospace Sciences Meeting, January 2004.

4. Mellis, Matthew; Carney, Kelly; Gabrys, Jonathan; Fasanella, Edwin L.; and Lyle, Karen H. "A Summary of the Space Shuttle Columbia Tragedy and the Use of LS-DYNA in the Accident Investigation and Return-to-Flight Efforts”, Presented at the $8^{\text {th }}$ International LS-DYNA Users Conference, May 2004.

5. Carney, Kelly; Mellis, Matthew; Fasanella, Edwin L.; Lyle, Karen H.; and Gabrys, Jonathan. "Material Modeling of Space Shuttle Leading Edge and External Tank Materials for use in the Columbia Accident Investigation,” Presented at the $8^{\text {th }}$ International LS-DYNA Users Conference, Mary 2004.

6. Weiser, Erik S.; St. Clair, Terry L.; and Nemeth, Michael P. Assessment of Technologies for the Space Shuttle External Tank Thermal Protection System and Recommendations for Technology Improvement - Part 1: Materials Characterization and Analysis, NASA TM 2004-213238, July 2004.

7. Anastasi, Robert F. and Madaras, Eric I. "Application of Hilbert-Huang Transform for Improved Defect Detection in Terahertz NDE of Shuttle Tiles", Presented at the SPIE International Symposia on Smart Structures and Materials/NDE, March 2005.

8. Winfree, William. "Nondestructive Evaluation Technologies Applied to the External Tank", AIAA Paper 2005-3629, Presented at the 41 ${ }^{\text {st }}$ AIAA/ASME/SAE/ASEE Joint Propulsion Conference, July 2005.

9. Edwards, John L. "Aeroelastic Response and Protection of ET Cable Trays", AIAA Paper 2005-3627, Presented at the 41 $1^{\text {st }}$ AIAA/ASME/SAE/ASEE Joint Propulsion Conference, July 2005.

10. Stockwell, Alan E. The Influence of Model Complexity on the Impact Response of a Shuttle Leading-Edge Finite Element Simulation. NASA CR-2005-213535, March 2005.

11. Jackson, Karen E.; Fasanella, Edwin L.; Llye, Karen H.; and Spellman, Regina L. The Influence of Clocking Angle of the Projectile on the Simulated Impact Response on a Shuttle Leading Edge Wing Panel. NASA TM-2005213538, March 2005. 
12. Jackson, Karen E.; Fasanella, Edwin L.; Lyle, Karen H.; and Spellman, Regina L. The Influence of Mesh Density on the Impact Response of a Shuttle Leading-Edge Wing Panel Finite Element Simulation, NASA TM2004-213501, November 2004.

13. Fasanella, Edwin L.; Lyle, Karen H.; Gabrys, Jonathan; Mellis, Matthew; and Carney, Kelly. "Test and Analysis Correlation of Foam Impact onto Space Shuttle Wing Leading Edge RCC Panel 8”, Presented at the 8 International LS-DYNA Users Conference, May 2004.

14. Horta, Lucas G. and Kurtz-Husch, Jeanette D. Structures and Materials Experimental Facilities and Capabilities Catalog. NASA TM-2000-210294, June 2000.

15. Micol, J.R. "Langley Aerothermodynamic Facilities Complex: Enhancements and Test Capabilities,” AIAA Paper 98-0147, January 1998.

16. Merski, N.R. Relative-Intensity Two-Color Phosphor Thermography System”, NASA Technical Memoradum TM-104123, 1991.

17. Wood, William A.; Pulsonetti, Maria V.; Everhart, Joel L.; and Bey, Kim S. “Assessment of LAURA for Laminar Supersonic Shallow Cavities”, AIAA Paper 2004-2639, June 2004.

18. Berry, Scott and Hamilton, Harris. "Discrete Roughness Effects on the Shuttle Orbiter at Mach 6", AIAA Paper 2002-2714, June 2002.

19. Reuther, James J.; Prabhu, Dinesh K.; Brown, James L.; Wright, Michael J.; and Saunders, David A. “Computational Fluid Dynamics for Wing Re-Entry Vehicles at Hypersonic Conditions”, AIAA Paper 2004-2537, June 2004.

20. Alter, Stephen J.; Reuther, James J.; and McDaniel, Ryan D. "Development of a Flexible Framework for Hypersonic Navier-Stokes Shuttle Orbiter Meshes”, AIAA Paper 2004-2635, June 2004.

21. Gnoffo, Peter A. and Alter, Stephen J. "Simulation of Flow Through Breach in Leading Edge at Mach 24”, AIAA Paper 2004-2283, June 2004.

22. Stephan, Ryan A.; Johnson, David G.; Mastropietro, A.J.; and Ancarrow, Walt C. "Development of Detectability Limits for On-Orbit Inspection of Space Shuttle Wing Leading Edge”, Presented at the SPIE Defense and Security Symposium 2005, March 2005.

23. Harvey, Gale A.; Humes, Donald H.; and Siochi, Emile J. "Vacuum/Zero Net-Gravity Application for OnOrbit TPS Tile Repair”, Presented at the $23^{\text {rd }}$ Space Simulation Conference, November 2004. 